\title{
Spinopelvic sagittal imbalance as a risk factor for adjacent-segment disease after single-segment posterior lumbar interbody fusion
}

\author{
Tomiya Matsumoto, MD, PhD, Shinya Okuda, MD, PhD, Takafumi Maeno, MD, PhD, \\ Tomoya Yamashita, MD, Ryoji Yamasaki, MD, PhD, Tsuyoshi Sugiura, MD, PhD, and \\ Motoki Iwasaki, MD, PhD \\ Department of Orthopaedic Surgery, Osaka Rosai Hospital, Sakai, Japan
}

OBJECTIVE The importance of spinopelvic balance and its implications for clinical outcomes after spinal arthrodesis has been reported in recent studies. However, little is known about the relationship between adjacent-segment disease (ASD) after lumbar arthrodesis and spinopelvic alignment. The purpose of this study was to clarify the relationship between spinopelvic radiographic parameters and symptomatic ASD after L4-5 single-level posterior lumbar interbody fusion (PLIF).

METHODS This was a retrospective 1:5 matched case-control study. Twenty patients who had undergone revision surgery for symptomatic ASD after L4-5 PLIF and had standing radiographs of the whole spine before primary and revision surgeries were enrolled from 2005 to 2012. As a control group, 100 age-, sex-, and pathology-matched patients who had undergone L4-5 PLIF during the same period, had no signs of symptomatic ASD for more than 3 years, and had wholespine radiographs at preoperation and last follow-up were selected. Mean age at the time of primary surgery was 68.9 years in the ASD group and 66.7 years in the control group. Several radiographic spinopelvic parameters were measured as follows: sagittal vertical axis (SVA), thoracic kyphosis (TK), sacral slope (SS), pelvic tilt (PT), pelvic incidence (PI), lumbar lordosis (LL), and segmental lordosis at L4-5 (SL) in the sagittal view, and C7-central sacral vertical line (C7-CSVL) in the coronal view. Radiological parameters were compared between the groups.

RESULTS No significant change was found between pre- and postoperative radiographic parameters in each group. In terms of preoperative radiographic parameters, the ASD group had significantly lower LL $\left(40.7^{\circ} \mathrm{vs} 47.2^{\circ}, p<0.01\right)$ and significantly higher PT $\left(27^{\circ}\right.$ vs $\left.22.9^{\circ}, p<0.05\right)$ than the control group. SVA $\geq 50 \mathrm{~mm}$ was observed in 10 of 20 patients $(50 \%)$ in the ASD group and in 21 of 100 patients $(21 \%, p<0.01)$ in the control group. $\mathrm{PI}-\mathrm{LL} \geq 10^{\circ}$ was noted in 15 of 20 patients $(75 \%)$ in the ASD group and in 40 of 100 patients $(40 \%, p<0.01)$ in the control group on preoperative radiographs. Postoperatively, the ASD group had significantly lower TK $\left(22.5^{\circ}\right.$ vs $\left.30.9^{\circ}, p<0.01\right)$ and lower LL $\left(39.3^{\circ}\right.$ vs $\left.48.1^{\circ}, p<0.05\right)$ than the control group had. PI-LL $\geq 10^{\circ}$ was seen in 15 of 20 patients $(75 \%)$ in the ASD group and in 43 of 100 patients $(43 \%, p<0.01)$ in the control group.

CONCLUSIONS Preoperative global sagittal imbalance (SVA>50 mm and higher PT), pre- and postoperative lower LL, and PI-LL mismatch were significantly associated with ASD. Therefore, even with a single-level PLIF, appropriate SL and $\mathrm{LL}$ should be obtained at surgery to improve spinopelvic sagittal imbalance. The results also suggest that the achievement of the appropriate LL and PI-LL prevents ASD after L4-5 PLIF.

https://thejns.org/doi/abs/10.3171/2016.9.SPINE16232

KEY WORDS spinopelvic sagittal imbalance; adjacent-segment disease; posterior lumbar interbody fusion

A LTHOUGH posterior lumbar interbody fusion (PLIF) with pedicle screw fixation has produced satisfactory clinical results, solid fusion has been reported to accelerate degenerative changes at adjacent unfused levels..$^{9,19,21}$ This spinal pathology is well known as adjacent-segment disease (ASD). Previous studies have reported on the incidence of ASD after lumbar spinal fusion, with radiological ASD in $36 \%-84 \%$ of patients and symptomatic ASD in $0 \%-24 \%$ of patients. ${ }^{9} 10,12,13,15-17,24$ In terms of the risk factors for ASD after lumbar spinal fu-

ABBREVIATIONS ASD = adjacent-segment disease; CSVL = central sacral vertical line; LL = lumbar lordosis; PI = pelvic incidence; PLIF = posterior lumbar interbody fusion; PT = pelvic tilt; SL = segmental lordosis; SS = sacral slope; SVA = sagittal vertical axis; TK = thoracic kyphosis.

SUBMITTED February 25, 2016. ACCEPTED September 12, 2016.

INCLUDE WHEN CITING Published online January 6, 2017; DOI: 10.3171/2016.9.SPINE16232. 
sion, numerous studies have reported patient-associated factors, such as age, sex, obesity, preexisting degeneration, and facet tropism, and surgery-associated factors such as the number of fused segments, disc height distraction, the method of fusion, and a lower lordotic angle of the fused segment. ${ }^{11,15,19,21}$

The importance of spinopelvic sagittal balance and its implications for clinical outcomes of spinal arthrodesis or decompression of the degenerative lumbar spine has been shown in recent studies. ${ }^{714}$ Additionally, it has been suggested that spinopelvic sagittal alignment may contribute to ASD. ${ }^{5,13,21}$ However, most of these studies of the relationships between spinopelvic sagittal alignment and ASD did not evaluate standing radiographs of the whole spine, and they included various numbers of fused segments and levels of fusion that affect spinopelvic sagittal alignment. Therefore, little is still known about the relationship between spinopelvic alignment and ASD. To exclude other factors in the current study, the patients were limited to those with degenerative lumbar disorders at L4-5 using the same instrumentation and the same fusion technique. The purpose of this study was to clarify the relationship between spinopelvic radiographic parameters and symptomatic ASD after L4-5 single-level PLIF.

\section{Methods \\ Subjects}

This study was a retrospective 1:5 matched case-control study. The subjects in this study were limited to patients who had undergone L4-5 PLIF. Twenty patients who had undergone revision surgery for symptomatic ASD after L4-5 PLIF and had standing radiographs of the whole spine before primary and revision surgeries were enrolled from 2005 to 2012. Eighteen patients had degenerative spondylolisthesis, 1 had lumbar foraminal stenosis, and 1 had recurrence of lumbar disc herniation. The exclusion criterion was the presence of scoliosis (Cobb angle $>20^{\circ}$ ). The reason for the revision surgery was newly developed neurological symptoms of the lower extremities in all cases. The ASD occurred in the proximal segment in 16 patients and in the distal segment in 4 patients. The pathology in ASD was spondylolisthesis with instability in 8 patients, adjacent-segment stenosis in 10 patients, lumbar disk herniation in 2 patients, and pseudoarthrosis in no patients. PLIF was performed in 11 patients, posterior decompression without fusion was performed in 7 patients, and lumbar disc herniotomy was performed in 2 patients for ASD. All patients recovered from the neurological symptoms of the lower extremities after revision surgery. As a control group, 100 age-, sex-, and pathology-matched patients who had undergone L4-5 PLIF during the same period and had no signs of symptomatic ASD for more than 3 years were selected. Symptomatic ASD was defined as a condition in which additional surgery was required to treat neurological deterioration. Mean age at the time of primary surgery was 68.9 years (range $37-84$ years) in the ASD group and 66.7 years (range $43-86$ years) in the control group. There were 9 men and 11 women in the ASD group and 40 men and 60 women in the control group (Table 1).
TABLE 1. Patient demographics

\begin{tabular}{cccc}
\hline Parameter & $\begin{array}{c}\text { ASD Group } \\
(\mathrm{n}=20)\end{array}$ & $\begin{array}{c}\text { Control Group } \\
(\mathrm{n}=100)\end{array}$ & p Value \\
\hline Age $(\mathrm{yrs})$ & & & \\
\hline Mean (SD) & $68.9(9.9)$ & $66.7(7.5)$ & 0.26 \\
\hline Range & $37-84$ & $43-86$ & \\
\hline Sex (M/F) & $9 / 11$ & $40 / 60$ & 0.67 \\
\hline BMI (kg/m $\left.{ }^{2}\right)$ & & & \\
\hline Mean (SD) & $24.9(4.1)$ & $23.7(3.4)$ & 0.15 \\
\hline Range & $18.9-38.4$ & $15.5-32.9$ & \\
\hline Follow-up (mos) & & & \\
\hline Mean (SD) & $37.0(24)$ & $68.6(27.2)$ & $<0.01$ \\
\hline Range & $3-77$ & $36-120$ & \\
\hline Disease & & & \\
\hline DS & 18 & 94 & \\
\hline FS & 1 & 3 & \\
\hline DH & 1 & 3 & \\
\hline
\end{tabular}

$\mathrm{BMI}=$ body mass index; $\mathrm{DH}=$ disc herniation; $\mathrm{DS}=$ degenerative spondylolis thesis; FS = foraminal stenosis.

\section{Surgical Procedure}

All procedures were performed using the same technique described elsewhere. ${ }^{18}$ Briefly, bilateral total facetectomy, subtotal discectomy, and local autologous bone graft with 2 Brantigan's rectangular cages (DePuy Spine) were performed. Finally, instrumentation was added using the Steffee Variable Spine Plating System (DePuy Spine). The posterior iliac crest bone was not harvested. Posterolateral fusion was not performed at any level.

\section{Radiological Evaluations}

All patients underwent standing radiographs of the whole spine with inclusion of the femoral heads. Radiological measurements in the ASD group were examined preoperatively and just before revision surgery, whereas those in the control group were examined preoperatively and at the final follow-up. The average time of postoperative radiographs was 37.0 months (range 3-77 months) in the ASD group and 68.6 months (range 36-120 months) in the control group. Several radiographic spinopelvic parameters were measured as follows: sagittal vertical axis (SVA), thoracic kyphosis (TK), sacral slope (SS), pelvic tilt (PT), pelvic incidence (PI), lumbar lordosis (LL) and segmental lordosis at L4-5 (SL) in the sagittal view, and C7-central sacral vertical line (C7-CSVL) in the coronal view. To evaluate preoperative ASD, the adjacent-segment facet joint on CT and the adjacent-segment disc height on standing lateral radiographs were examined. The degree of facet joint degeneration was classified into Grades 0-3 according to the Weishaupt grading system, as follows: Grade 0 , normal facet joint space (2-4 $\mathrm{mm}$ width); Grade 1 , narrowing of the facet joint $(<2 \mathrm{~mm})$ and/or small osteophytes and/or mild hypertrophy of the articular process; Grade 2, narrowing of the facet joint space and/or moderate osteophytes and/or moderate hypertrophy of the articular process and/or mild subarticular bone erosions; and Grade 3, narrowing of the facet joint space and/or 
TABLE 2. Evaluations of preoperative ASD

\begin{tabular}{lcc}
\hline \multicolumn{1}{c}{ Parameter } & ASD Group & Control Group \\
\hline No. of patients & 20 & 100 \\
\hline L3-4 & & \\
\hline Mean disc height in mm (SD) & $8.0(1.7)$ & $8.5(1.8)$ \\
\hline Facet grade & & \\
\hline 0 & 4 & 15 \\
\hline 1 & 7 & 44 \\
\hline 2 & 4 & 27 \\
\hline 3 & 5 & 14 \\
\hline L5-S1 & & \\
\hline Mean disc height in mm (SD) & $7.3(2.4)$ & $7.5(2.2)$ \\
\hline Facet grade & & 24 \\
\hline 0 & 6 & 42 \\
\hline 1 & 10 & 21 \\
\hline 2 & 4 & 13 \\
\hline 3 & 0 & \\
\hline
\end{tabular}

All $p$ values were nonsignificant.

large osteophytes and/or severe hypertrophy of the articular process and/or severe subarticular bone erosion and/or subchondral cysts. ${ }^{28}$

SVA was measured as the distance between the C-7 plumb line and the superior posterior corner of the S-1 vertebral body in the lateral radiograph. TK was measured from the upper endplate of T-5 to the lower endplate of $\mathrm{T}-12$. SS was measured as the angle between the endplate of S-1 and a horizontal line. PT was measured as the angle between the vertical line and the line connecting the midpoint of the sacral plate to the femoral head axis. PI was measured as the angle between the line perpendicular to the sacral plate at its midpoint and the line connecting this point to the femoral head axis. LL was measured from the upper endplate of L-1 to the lower endplate of S-1. SL at L4-5 was measured from the upper endplate of L-4 to the lower endplate of L-5. C7-CSVL was measured as the distance between the C-7 plumb line and the midpoint of the sacrum in the coronal radiograph. PI minus LL (PILL) was divided into 2 categories: appropriate (PI-LL < $10^{\circ}$ ) and mismatch (PI-LL $\geq 10^{\circ}$ ). SVA was divided into 2 categories: balanced (SVA $<50 \mathrm{~mm})$ and imbalanced $(\mathrm{SVA} \geq 50 \mathrm{~mm})^{2,22,25}$

\section{Statistical Analysis}

Radiological factors were compared between the 2 groups and within the groups using the Student t-test for continuous variables and the chi-square test for categorical variables. All statistical analyses were performed using IBM SPSS Statistics for Windows (version 21, IBM Corp.). A p value $<0.05$ was considered significant.

\section{Results}

No significant differences were found in the grade of adjacent-segment facet joints and adjacent disc height (Table 2). Preoperative average percentage slip (in patients with degenerative spondylolisthesis) was $17.4 \% \pm$
TABLE 3. Pre- and postoperative radiographic parameters in the ASD group

\begin{tabular}{lll}
\hline \multicolumn{1}{c}{ Parameter } & \multicolumn{1}{c}{$\begin{array}{c}\text { Preop } \\
\text { Parameters }\end{array}$} & $\begin{array}{c}\text { Postop } \\
\text { Parameters }\end{array}$ \\
\hline No. of patients & 20 & 20 \\
\hline SVA $\geq 50$ mm (\%) & $10(50)$ & $9(45)$ \\
\hline Mean TK in degrees (SD) & $24.7(10.8)$ & $22.5(11.2)$ \\
\hline Mean SS in degrees (SD) & $32.7(6.7)$ & $33.0(7.6)$ \\
\hline Mean PT in degrees (SD) & $27.0(6.2)$ & $26.4(6.1)$ \\
\hline Mean PI in degrees (SD) & $59.7(8.3)$ & $59.4(8.4)$ \\
\hline Mean LL in degrees (SD) & $40.7(9.6)$ & $39.3(13.5)$ \\
\hline PI-LL $\geq 10^{\circ}$ (\%) & $15(75)$ & $15(75)$ \\
\hline Mean SL at L4-5 in degrees (SD) & $11.4(8.5)$ & $12.9(6.9)$ \\
\hline Mean C7-CSVL in mm (\%) & $12.2(9.2)$ & $12.7(11.2)$ \\
\hline Alp
\end{tabular}

All $p$ values were nonsignificant.

9.7\% in the ASD group and $17.2 \% \pm 6.9 \%$ in the control group, whereas postoperative average percentage slip was $3.1 \% \pm 6.3 \%$ in the ASD group and $4.5 \% \pm 6.6 \%$ in the control group. There were no significant differences in pre- and postoperative percentage slip between the groups. No significant changes were found between preand postoperative radiographic parameters in each group (Tables 3 and 4).

\section{Comparison of the Preoperative Radiographic Parameters Between Groups}

The ASD group had significantly lower LL $\left(40.7^{\circ}\right.$ vs $\left.47.2^{\circ}, \mathrm{p}<0.01\right)$ and significantly higher PT $\left(27^{\circ}\right.$ vs $22.9^{\circ}$, $\mathrm{p}<0.05)$ than the control group. SVA $\geq 50 \mathrm{~mm}$ was observed in 10 of 20 patients (50\%) in the ASD group and in 21 of 100 patients $(21 \%)$ in the control group. PI-LL $\geq 10^{\circ}$ was observed in 15 of 20 patients (75\%) in the ASD group and in 40 of 100 patients $(40 \%)$ in the control group on preoperative radiographs. The rates of SVA $\geq 50 \mathrm{~mm}$ and PI-LL $\geq 10^{\circ}$ were significantly higher in the ASD group (Fig. 1). No significant differences were found in other

TABLE 4. Pre- and postoperative radiographic parameters in the control group

\begin{tabular}{lll}
\hline \multicolumn{1}{c}{ Parameter } & $\begin{array}{c}\text { Preop } \\
\text { Parameters }\end{array}$ & $\begin{array}{c}\text { Postop } \\
\text { Parameters }\end{array}$ \\
\hline No. of patients & 100 & 100 \\
\hline SVA $\geq 50$ mm (\%) & $21(21)$ & $24(24)$ \\
\hline Mean TK in degrees (SD) & $29.4(9.8)$ & $30.9(10.3)$ \\
\hline Mean SS in degrees (SD) & $33.8(7.2)$ & $34.6(7.5)$ \\
\hline Mean PT in degrees (SD) & $22.9(7.8)$ & $22.6(7.8)$ \\
\hline Mean PI in degrees (SD) & $56.8(9.1)$ & $57.3(9.7)$ \\
\hline Mean LL in degrees (SD) & $47.2(10.2)$ & $48.1(10.9)$ \\
\hline PI-LL $\geq 10^{\circ}$ (\%) & $40(40)$ & $43(43)$ \\
\hline Mean SL at L4-5 in degrees (SD) & $14.0(5.8)$ & $12.8(6.2)$ \\
\hline Mean C7-CSVL in mm (\%) & $9.5(7.7)$ & $10.0(8.8)$ \\
\hline All
\end{tabular}

All $p$ values were nonsignificant. 


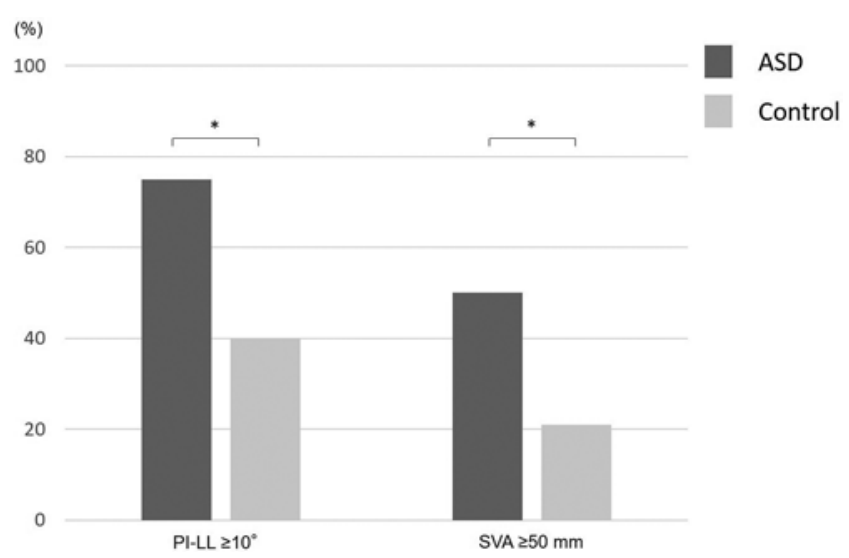

FIG. 1. The rate of revision surgery for ASD according to preoperative parameters. The rates of SVA $\geq 50 \mathrm{~mm}$ and $\mathrm{PI}-\mathrm{LL} \geq 10^{\circ}$ were significantly higher in the ASD group. ${ }^{*} p<0.01$.

preoperative radiological parameters, such as TK, PI, SS, SL at L4-5, and C7-CSVL (Table 5).

\section{Comparison of the Postoperative Radiographic Parameters Between Groups}

The ASD group had significantly lower TK $\left(22.5^{\circ}\right.$ vs $\left.30.9^{\circ}, \mathrm{p}<0.01\right)$, significantly lower LL $\left(39.3^{\circ}\right.$ vs $48.1^{\circ}, \mathrm{p}<$ $0.05)$, and significantly higher PT $\left(26.4^{\circ}\right.$ vs $\left.22.6^{\circ}, \mathrm{p}<0.05\right)$ than the control group had. PI-LL $\geq 10^{\circ}$ was observed in 15 of 20 patients (75\%) in the ASD group and in 43 of 100 patients $(43 \%$; $p<0.01)$ in the control group. No significant differences were found in other postoperative radiological parameters (Table 6).

\section{Discussion}

ASD after PLIF is one of the most important sequelae affecting long-term results. ${ }^{19}$ To the best of our knowledge, the present study is the first to examine the relationships between spinopelvic radiographic parameters and ASD after PLIF with a limitation on the level of fusion and the number of fusions using standing radiographs of the whole spine. Patients with revision surgery for ASD after

TABLE 5. Comparison of preoperative radiographic parameters between the ASD and control groups

\begin{tabular}{lllr}
\hline \multicolumn{1}{c}{ Parameter } & \multicolumn{1}{c}{$\begin{array}{c}\text { ASD } \\
\text { Group }\end{array}$} & $\begin{array}{c}\text { Control } \\
\text { Group }\end{array}$ & $\begin{array}{c}\text { p } \\
\text { Value }\end{array}$ \\
\hline No. of patients & 20 & 100 & \\
\hline SVA $\geq 50$ mm (\%) & $10(50 \%)$ & $21(21 \%)$ & $<0.01$ \\
\hline Mean TK in degrees (SD) & $24.7(10.8)$ & $29.4(9.8)$ & 0.13 \\
\hline Mean SS in degrees (SD) & $32.7(6.7)$ & $33.8(7.2)$ & 0.50 \\
\hline Mean PT in degrees (SD) & $27.0(6.2)$ & $22.9(7.8)$ & $<0.05$ \\
\hline Mean PI in degrees (SD) & $59.7(8.3)$ & $56.8(9.1)$ & 0.19 \\
\hline Mean LL in degrees (SD) & $40.7(9.6)$ & $47.2(10.2)$ & $<0.01$ \\
\hline PI-LL $\geq 10^{\circ}(\%)$ & $15(75 \%)$ & $40(40 \%)$ & $<0.01$ \\
\hline Mean SL at L4-5 in degrees (SD) & $11.4(8.5)$ & $14.0(5.8)$ & 0.20 \\
\hline Mean C7-CSVL in mm (\%) & $12.2(9.2)$ & $9.5(7.7)$ & 0.17 \\
\hline
\end{tabular}

TABLE 6. Comparison of postoperative radiographic parameters between the ASD and control groups

\begin{tabular}{lllr}
\hline \multicolumn{1}{c}{ Parameter } & \multicolumn{1}{c}{$\begin{array}{c}\text { ASD } \\
\text { Group }\end{array}$} & $\begin{array}{c}\text { Control } \\
\text { Group }\end{array}$ & $\begin{array}{r}\text { p } \\
\text { Value }\end{array}$ \\
\hline No. of patients & 20 & 100 & \\
\hline SVA $\geq 50$ mm (\%) & $9(45 \%)$ & $24(24 \%)$ & 0.056 \\
\hline Mean TK in degrees (SD) & $22.5(11.2)$ & $30.9(10.3)$ & $<0.01$ \\
\hline Mean SS in degrees (SD) & $33.0(7.6)$ & $34.6(7.5)$ & 0.37 \\
\hline Mean PT in degrees (SD) & $26.4(6.0)$ & $22.6(7.8)$ & $<0.05$ \\
\hline Mean PI in degrees (SD) & $59.4(8.4)$ & $57.3(9.7)$ & 0.36 \\
\hline Mean LL in degrees (SD) & $39.3(13.5)$ & $48.1(10.9)$ & $<0.05$ \\
\hline PI-LL $\geq 10^{\circ}(\%)$ & $15(75 \%)$ & $43(43 \%)$ & $<0.01$ \\
\hline Mean SL at L4-5 in degrees (SD) & $12.9(6.9)$ & $12.8(6.2)$ & 0.89 \\
\hline Mean C7-CSVL in mm (\%) & $12.7(11.2)$ & $10.0(8.8)$ & 0.25 \\
\hline
\end{tabular}

L4-5 PLIF had global sagittal imbalance in preoperative radiographs and lower LL and PI-LL mismatch (PI-LL $\geq$ $10^{\circ}$ ) in pre- and postoperative radiographs.

Some studies have suggested that abnormal sagittal spinopelvic parameters play a significant role in ASD after lumbar fusion. ${ }^{5,13,14}$ Kumar et al. reviewed 83 patients with degenerative disc disease and concluded that patients who had an abnormal C-7 plumb line position and/or SS had a significantly higher rate of ASD..$^{13}$ Di Martino et al. reported that patients with $\mathrm{PT}>20^{\circ}$ and $\mathrm{SS}<40^{\circ}$ were at higher risk than others for clinically evident ASD. ${ }^{5}$ However, they evaluated the pre-revision operative radiographic parameters and could not evaluate spinopelvic parameters in the native whole spine. In this study, patients in the ASD group had significantly higher PT and SVA than those in the control group in the native standing radiographs of the whole spine. Therefore, preoperative global sagittal alignment of the spine was associated with symptomatic ASD after L4-5 PLIF.

LL has also been extensively studied in patients with ASD. ${ }^{3,6}$ Djurasovic et al. reported that patients who developed ASD had significantly less lordosis, both through their fusion levels and through the entire lumbar spine, following their index surgery compared with matched control patients. ${ }^{6}$ However, it was difficult to determine the appropriate LL for an individual. On the other hand, Nakashima reported that a high degree of PI was a risk factor for radiographic ASD. ${ }^{17} \mathrm{PI}$ has subsequently been generally acknowledged as a predictor of the amount of LL required to assume a balanced sagittal posture ${ }^{4,8}$ In the first place, it has been reported that PI-LL mismatch was found to have the strongest correlation with disability and lower quality of life scores in adult patients with spinal deformity. ${ }^{25}$ Therefore, to date, the balance of PI-LL has been considered the index in the corrective surgical management of adult deformity. Additionally, some reports have described the association between PI-LL mismatch and ASD. ${ }^{23,26}$ Senteler et al., in a biomechanical study with musculoskeletal modeling, reported that patients with PILL mismatch had increased segmental joint loads in the unfused and fused lumbar spine. ${ }^{26}$ Moreover, Rothenfluh et al. reviewed 84 patients after lumbar posterolateral 
fusion of 1,2, or 3 segments between L-2 and S-1 and showed that patients with ASD had a higher difference between PI and LL. ${ }^{23}$ They also reported that patients with PI-LL mismatch $\left(\mathrm{PI}-\mathrm{LL} \geq 10^{\circ}\right.$ ) had a 10 -fold greater risk of developing ASD than controls had. In the present study, lower LL and PI-LL mismatch were significantly associated with ASD after L4-5 PLIF. These results suggest that it is necessary to focus attention on the balance of PI-LL in not only long spinal fusion for adult spinal deformity, but also in single-level PLIF for degenerative lumbar disease. The results also suggest the possibility that achieving the appropriate LL and PI-LL prevents ASD after L4-5 PLIF.

Several studies have reported that SL in the fused segment involved in LL is a risk factor for ASD.,12,27 In the study reported here, no significant changes were noted between pre- and postoperative SL, and SL was not associated with ASD. However, Umehara et al. reported in their biomechanical study that hypolordosis in the instrumented segments caused increased loading of the posterior column of the adjacent segments. ${ }^{27}$ Furthermore, Kim et al. suggested that maintaining the L4-5 segmental lordotic angle at about $\geq 20^{\circ}$ was important for prevention of clinical ASD. ${ }^{12}$ Previously, we have reported on a repeated ASD case caused by lower SL and LL. ${ }^{20}$ Therefore, our current strategy is that appropriate SL and LL should be obtained at surgery to prevent ASD, even with single-level PLIF. We should consider various ways, such as using hyper wedge cages, to obtain larger SL and LL. If lower SL and LL remain after single-level PLIF, when correction surgery for spinal deformity becomes necessary, surgery combined with more invasive surgical management, such as vertebral column resection or spinal osteotomy, is required to obtain an appropriate LL and PI-LL.

The present study has several limitations. First, it was a retrospective review of a small number of patients. Second, spinopelvic radiographic parameters were not evaluated immediately after surgery. Third, it was not possible to analyze all risk factors for ASD that were previously reported. Further prospective longitudinal studies are needed to identify the proper operative methods for patients having a degenerative lumbar spine with global sagittal imbalance and/or PI-LL mismatch.

\section{Conclusions}

The relationships between revision surgery for symptomatic ASD after L4-5 PLIF and spinopelvic radiographic parameters were investigated. Preoperative global sagittal imbalance (SVA $\geq 50 \mathrm{~mm}$ and higher PT), and pre- and postoperative lower LL and PI-LL mismatch were significantly associated with ASD. Therefore, even with a single-level PLIF, appropriate SL and LL should be obtained at surgery to improve global sagittal imbalance and PI-LL mismatch. The results of this study suggest the possibility that achieving the appropriate LL and PI-LL prevents ASD after L4-5 PLIF.

\section{References}

1. Akamaru T, Kawahara N, Tim Yoon S, Minamide A, Su Kim $\mathrm{K}$, Tomita K, et al: Adjacent segment motion after a simulated lumbar fusion in different sagittal alignments: a bio- mechanical analysis. Spine (Phila Pa 1976) 28:1560-1566, 2003

2. Baghdadi YM, Larson AN, Dekutoski MB, Cui Q, Sebastian AS, Armitage BM, et al: Sagittal balance and spinopelvic parameters after lateral lumbar interbody fusion for degenerative scoliosis: a case-control study. Spine (Phila Pa 1976) 39:E166-E173, 2014

3. Been E, Kalichman L: Lumbar lordosis. Spine J 14:87-97, 2014

4. Boulay C, Tardieu C, Hecquet J, Benaim C, Mouilleseaux B, Marty C, et al: Sagittal alignment of spine and pelvis regulated by pelvic incidence: standard values and prediction of lordosis. Eur Spine J 15:415-422, 2006

5. Di Martino A, Quattrocchi CC, Scarciolla L, Papapietro N, Beomonte Zobel B, Denaro V: Estimating the risk for symptomatic adjacent segment degeneration after lumbar fusion: analysis from a cohort of patients undergoing revision surgery. Eur Spine J 23 (Suppl 6):693-698, 2014

6. Djurasovic MO, Carreon LY, Glassman SD, Dimar JR II, Puno RM, Johnson JR: Sagittal alignment as a risk factor for adjacent level degeneration: a case-control study. Orthopedics 31:546, 2008

7. Dohzono S, Toyoda H, Matsumoto T, Suzuki A, Terai H, Nakamura H: The influence of preoperative spinal sagittal balance on clinical outcomes after microendoscopic laminotomy in patients with lumbar spinal canal stenosis. J Neurosurg Spine 23:49-54, 2015

8. Duval-Beaupère G, Schmidt C, Cosson P: A Barycentremetric study of the sagittal shape of spine and pelvis: the conditions required for an economic standing position. Ann Biomed Eng 20:451-462, 1992

9. Ghiselli G, Wang JC, Bhatia NN, Hsu WK, Dawson EG: Adjacent segment degeneration in the lumbar spine. J Bone Joint Surg Am 86-A:1497-1503, 2004

10. Imagama S, Kawakami N, Kanemura T, Matsubara Y, Tsuji T, Ohara T, et al: Radiographic adjacent segment degeneration at five years after L4/5 posterior lumbar interbody fusion with pedicle screw instrumentation: evaluation by computed tomography and annual screening with magnetic resonance imaging. J Spinal Disord Tech [epub ahead of print], 2013

11. Kaito T, Hosono N, Mukai Y, Makino T, Fuji T, Yonenobu K: Induction of early degeneration of the adjacent segment after posterior lumbar interbody fusion by excessive distraction of lumbar disc space. J Neurosurg Spine 12:671-679, 2010

12. Kim KH, Lee SH, Shim CS, Lee DY, Park HS, Pan WJ, et al: Adjacent segment disease after interbody fusion and pedicle screw fixations for isolated L4-L5 spondylolisthesis: a minimum five-year follow-up. Spine (Phila Pa 1976) 35:625-634, 2010

13. Kumar MN, Baklanov A, Chopin D: Correlation between sagittal plane changes and adjacent segment degeneration following lumbar spine fusion. Eur Spine J 10:314-319, 2001

14. Le Huec JC, Faundez A, Dominguez D, Hoffmeyer P, Aunoble $\mathrm{S}$ : Evidence showing the relationship between sagittal balance and clinical outcomes in surgical treatment of degenerative spinal diseases: a literature review. Int Orthop 39:87-95, 2015

15. Lee JC, Kim Y, Soh JW, Shin BJ: Risk factors of adjacent segment disease requiring surgery after lumbar spinal fusion: comparison of posterior lumbar interbody fusion and posterolateral fusion. Spine (Phila Pa 1976) 39:E339-E345, 2014

16. Min JH, Jang JS, Lee SH: Comparison of anterior- and posterior-approach instrumented lumbar interbody fusion for spondylolisthesis. J Neurosurg Spine 7:21-26, 2007

17. Nakashima H, Kawakami N, Tsuji T, Ohara T, Suzuki Y, Saito T, et al: Adjacent segment disease after posterior lumbar interbody fusion: based on cases with a minimum of 10 
years of follow-up. Spine (Phila Pa 1976) 40:E831-E841, 2015

18. Okuda S, Oda T, Miyauchi A, Haku T, Yamamoto T, Iwasaki M: Surgical outcomes of posterior lumbar interbody fusion in elderly patients. Surgical technique. J Bone Joint Surg Am 89 (Suppl 2 Pt 2):310-320, 2007

19. Okuda S, Oda T, Miyauchi A, Tamura S, Hashimoto Y, Yamasaki S, et al: Lamina horizontalization and facet tropism as the risk factors for adjacent segment degeneration after PLIF. Spine (Phila Pa 1976) 33:2754-2758, 2008

20. Okuda S, Oda T, Yamasaki R, Maeno T, Iwasaki M: Repeated adjacent-segment degeneration after posterior lumbar interbody fusion. J Neurosurg Spine 20:538-541, 2014

21. Park P, Garton HJ, Gala VC, Hoff JT, McGillicuddy JE: Adjacent segment disease after lumbar or lumbosacral fusion: review of the literature. Spine (Phila Pa 1976) 29:19381944, 2004

22. Rose PS, Bridwell KH, Lenke LG, Cronen GA, Mulconrey DS, Buchowski JM, et al: Role of pelvic incidence, thoracic kyphosis, and patient factors on sagittal plane correction following pedicle subtraction osteotomy. Spine (Phila Pa 1976) 34:785-791, 2009

23. Rothenfluh DA, Mueller DA, Rothenfluh E, Min K: Pelvic incidence-lumbar lordosis mismatch predisposes to adjacent segment disease after lumbar spinal fusion. Eur Spine J 24:1251-1258, 2015

24. Sakaura H, Yamashita T, Miwa T, Ohzono K, Ohwada T: Outcomes of 2-level posterior lumbar interbody fusion for 2-level degenerative lumbar spondylolisthesis. J Neurosurg Spine 19:90-94, 2013

25. Schwab FJ, Blondel B, Bess S, Hostin R, Shaffrey CI, Smith JS, et al: Radiographical spinopelvic parameters and disability in the setting of adult spinal deformity: a prospective multicenter analysis. Spine (Phila Pa 1976) 38:E803-E812, 2013
26. Senteler M, Weisse B, Snedeker JG, Rothenfluh DA: Pelvic incidence-lumbar lordosis mismatch results in increased segmental joint loads in the unfused and fused lumbar spine. Eur Spine J 23:1384-1393, 2014

27. Umehara S, Zindrick MR, Patwardhan AG, Havey RM, Vrbos LA, Knight GW, et al: The biomechanical effect of postoperative hypolordosis in instrumented lumbar fusion on instrumented and adjacent spinal segments. Spine (Phila Pa 1976) 25:1617-1624, 2000

28. Weishaupt D, Zanetti M, Boos N, Hodler J: MR imaging and CT in osteoarthritis of the lumbar facet joints. Skeletal Radiol 28:215-219, 1999

\section{Disclosures}

The authors report no conflict of interest concerning the materials or methods used in this study or the findings specified in this paper.

\section{Author Contributions}

Conception and design: Matsumoto, Okuda, Maeno, Yamashita, Yamasaki, Iwasaki. Acquisition of data: Matsumoto. Analysis and interpretation of data: Matsumoto. Drafting the article: Matsumoto. Critically revising the article: Matsumoto, Okuda, Iwasaki. Reviewed submitted version of manuscript: Matsumoto, Okuda, Iwasaki. Approved the final version of the manuscript on behalf of all authors: Matsumoto. Statistical analysis: Matsumoto. Study supervision: Okuda, Maeno, Yamashita, Yamasaki, Sugiura, Iwasaki.

\section{Correspondence}

Tomiya Matsumoto, Department of Orthopaedic Surgery, Osaka Rosai Hospital, 1179-3 Nagasonecho, Kita-ku, Sakai 591-8025, Japan.email: tomiya@med.osaka-cu.ac.jp. 